\title{
Interplay of Inhibition and Excitation Shapes a Premotor Neural Sequence
}

\author{
(1)Georg Kosche, ${ }^{1,2 *}$ Daniela Vallentin, ${ }^{1,2 *}$ and Michael A. Long ${ }^{1,2}$ \\ ${ }^{1}$ Neuroscience Institute and Department of Otolaryngology, New York University Langone Medical Center, New York, New York 10016, and ${ }^{2}$ Center for \\ Neural Science, New York University, New York, New York 10003
}

In the zebra finch, singing behavior is driven by a sequence of bursts within premotor neurons located in the forebrain nucleus $\mathrm{HVC}$ (proper name). In addition to these excitatory projection neurons, HVC also contains inhibitory interneurons with a role in premotor patterning that is unclear. Here, we used a range of electrophysiological and behavioral observations to test previously described models suggesting discrete functional roles for inhibitory interneurons in song production. We show that single HVC premotor neuron bursts are sufficient to drive structured activity within the interneuron network because of pervasive and facilitating synaptic connections. We characterize interneuron activity during singing and describe reliable pauses in the firing of those neurons. We then demonstrate that these gaps in inhibition are likely to be necessary for driving normal bursting behavior in HVC premotor neurons and suggest that structured inhibition and excitation may be a general mechanism enabling sequence generation in other circuits.

Key words: behavior; circuit; inhibition; intracellular; neural sequence; premotor

\section{Introduction}

A wide variety of brain regions contain neural ensembles that become sequentially activated during behavior (Tanji, 2001; Jones et al., 2007; Pastalkova et al., 2008; Harvey et al., 2012; Peters et al., 2014), but the circuit mechanisms enabling these dynamics are in some cases poorly understood. The songbird has been a valuable model system for examining the network properties underlying sequence generation. An adult zebra finch (Taeniopygia guttata) can produce highly stereotyped singing behavior that is primarily driven by the forebrain nucleus HVC (Nottebohm et al., 1976; Vu et al., 1994; Long and Fee, 2008). Premotor HVC neurons project to the robust nucleus of the arcopallium (RA) and typically generate only one highfrequency burst at an invariant moment during the song motif (Hahnloser et al., 2002), as well as depolarizing synaptic potentials (see Fig. 1A) with timing and amplitude that are highly regular across renditions (Long et al., 2010). Different RA-projecting HVC neurons $\left(\mathrm{HVC}_{(\mathrm{RA})}\right)$ burst at different times and together they form a sequence (Hahnloser et al., 2002) that ultimately leads to the patterned activation of song-producing muscles (Fee

\footnotetext{
Received Oct. 20, 2014; revised Nov. 23, 2014; accepted Nov. 30, 2014.

Author contributions: G.K., D.V., and M.A.L. designed research; G.K. and D.V. performed research; G.K., D.V., and M.A.L. analyzed data; G.K., D.V., and M.A.L. wrote the paper.

This research was supported by the National Institutes of Health (Grant R01NS075044), The New York Stem Cell Foundation, and the Deutsche Forschungsgemeinschaft (Grant VA 742/1). We thankSam Benezra, Timothy Gardner, Robert Froemke, Daniel Okobi, Michel Picardo, Dmitry Rinberg, and Robin Tremblay for helpful comments on earlier versions of this manuscript and Kalman Katlowitz for assistance with statistics and analysis.

The authors declare no competing financial interests.

${ }^{*} G$.K. and D.V. contributed equally to this work.

Correspondence should be addressed to Michael A. Long, Neuroscience Institute and Department of Otolaryngology, New York University Langone Medical Center, 522 First Ave., SML 604, New York, NY 10016. E-mail: mlong@med.nyu.edu.

DOI:10.1523/JNEUROSCI.4346-14.2015

Copyright $\odot 2015$ the authors $\quad 0270-6474 / 15 / 351217-11 \$ 15.00 / 0$
}

et al., 2004). In addition to premotor neurons, nearly $10 \%$ of the total HVC population is GABAergic (Mooney, 2000; Wild et al., 2005; Scotto-Lomassese et al., 2007) and these local circuit interneurons represent the sole source of inhibition to HVC. Despite extensive characterization of the anatomical (Nixdorf et al., 1989; Mooney, 2000) and electrophysiological (Dutar et al., 1998; Kubota and Taniguchi, 1998; Mooney, 2000; Mooney and Prather, 2005) properties of HVC interneurons, the role of inhibition on HVC sequence generation remains a critical matter of interest.

Several network models have been proposed to explain the role of HVC inhibitory interneurons during song production. Because some HVC simulations can function properly in the absence of synaptic inhibition ( $\mathrm{Li}$ and Greenside, 2006), it has been speculated that interneurons may play only a minor role in generating song-related premotor patterns within HVC (Fig. 1B). Other modeling efforts have shown that the inclusion of a background level of unstructured inhibition (Fig. 1C) may facilitate the stable propagation of spiking activity through the network by limiting runaway excitation (Jin et al., 2007; Long et al., 2010). Alternatively, interneurons may play an active role in sequence generation by exhibiting patterned firing capable of providing a permissive gap or pause in inhibition that can shape the activity of $\mathrm{HVC}_{(\mathrm{RA})}$ neurons (Gibb et al., 2009; Fig. $1 D)$. Another model suggests that structured interneuron activity alone can be sufficient for sequentially activating $\mathrm{HVC}_{(\mathrm{RA})}$ neurons in the absence of precise feedforward excitatory circuitry (Yildiz and Kiebel, 2011; Fig. 1E). Here, we used a range of experimental techniques to investigate the synaptic interactions underlying a behaviorally relevant premotor sequence to provide a framework for understanding similar dynamics in other neural circuits. 


\section{Materials and Methods}

Animals. We used adult ( $>90 \mathrm{~d}$ after hatching) male zebra finches that were obtained from an outside breeder and maintained in a temperature- and humidity-controlled environment with a $12 / 12 \mathrm{~h}$ light/dark schedule. All animal maintenance and experimental procedures were performed according to the guidelines established by the Institutional Animal Care and Use Committee at the New York University Langone Medical Center.

Recording, perturbation, and analysis of singing behavior. Directed singing behavior was recorded using an omnidirectional lavalier microphone (AT 803b; Audio-Technica) that was clipped onto the cage of the male zebra finch. The songs were amplified using a Presonus Studio Channel amplifier and digitized at $40 \mathrm{kHz}$ with a National Instruments board. To quantify song similarity, we used Sound Analysis Pro 2011 (Tchernichovski et al., 2000) software $(p=0.05$, interval $=70 \mathrm{~ms}$, mininum duration $=15 \mathrm{~ms}$ applied to the entire motif) on 4-10 motifs from each bird and condition. Briefly, we obtained two different measures of song similarity: (1) “\% similarity” measures the probability that the compared songs are from the same bird and (2) "accuracy" measures the local similarity of sections of the motifs that are judged to be from the same bird. We defined the "global similarity" as the product of $\%$ similarity and accuracy. For the experiments in which the entirety of HVC was treated with a $\mathrm{GABA}_{\mathrm{A}}$ antagonist, gel foam sponges soaked in 0.015$0.025 \mathrm{~mm}$ gabazine were placed onto bilateral craniotomies $[1.2 \mathrm{~mm}$ (medial/lateral) $\times 0.7 \mathrm{~mm}$ (anterior/posterior)] overlying HVC. Control songs were recorded with the gel foam sponges soaked in PBS. For all experiments, variances are given as mean \pm SD. MATLAB was used for these analyses unless otherwise noted.

In vivo electrophysiology. The motorized intracellular microdrive was implanted in a manner similar to that described previously (Long et al., 2010). Briefly, the zebra finch was first anesthetized with isoflurane (1-3\% in oxygen). The base of the microdrive was then affixed to the skull of the bird using dental acrylic. For antidromic identification of projection neurons (Hahnloser et al., 2002), a bipolar stimulating electrode was implanted into RA and a reliable spike with minimal latency jitter $(<50 \mu$ s) could be evoked with single $200 \mu$ s current pulses of $<250$ $\mu \mathrm{A}$. We then prepared a $100-$ to $200-\mu \mathrm{m}$-diameter craniotomy above HVC and carefully removed overlying dura. A small protective "well" was built around the craniotomy using a silicone elastomer (Kwik-Cast; WPI). To protect the brain from desiccation, the well was filled with either PBS or a silicone gel (Dow Corning 10,000-60,000 cSt) during behavioral observations and with a layer of silicone elastomer overnight. For the electrophysiological experiments involving the unilateral pharmacological manipulation of HVC ("local microinfusion") in the singing zebra finch, the PBS within the well surrounding the HVC craniotomy was replaced with a mixture of gabazine (0.01-0.1 mM). In some cases, gabazine was introduced to the craniotomy in the freely behaving bird through a small silicone tube.

For intracellular recordings during singing, sharp electrodes with an impedance of 70-130 M $\Omega$ were prepared using a modified horizontal micropipette puller (P-97; Sutter Instruments) and filled with $3 \mathrm{M}$ potassium acetate. For juxtacellular recordings, electrodes with an impendance of 3-10 $\mathrm{M} \Omega$ were prepared and filled with $0.5 \mathrm{~m}$ sodium chloride. Zebra finches were briefly head fixed and partially immobilized in a foam restraint to allow for freshly prepared pipettes to be inserted into the microdrive. Once these electrodes were lowered into the brain and electrophysiological activity was observed, the bird was released and intra- cellular recordings were pursued by lowering the pipette through HVC in $\sim 5 \mu \mathrm{m}$ steps. A brief $(10-20 \mathrm{~ms})$ "buzz" pulse was often needed to facilitate the penetration of the membrane. Once a stable recording [for intracellular: spike height $>40 \mathrm{mV}$, resting membrane potential (RMP) $<-50 \mathrm{mV}$, recording duration $>3 \mathrm{~min}$; for juxtacellular: signal-to-noise ratio $>20$ ] was achieved, a female bird was presented to elicit directed singing. All membrane potential measurements were digitized at $40 \mathrm{kHz}$ using a National Instruments acquisition board and acquired with custom MATLAB software. A burst was defined as multiple spikes with an interspike interval of $<10 \mathrm{~ms}$.

In vivo data analysis. For the gap detection analysis, we considered all interneurons that were recorded for at least three motifs. The mean response of each interneuron (10 ms moving average, $1 \mathrm{~ms}$ resolution) was calculated and gaps were defined as time intervals $\geq 40 \mathrm{~ms}$ with a firing rate $\leq 5 \%$ of the mean firing rate. The gap overlap within a bird was quantified using a scoring system. A $1 \mathrm{~ms}$ sampled vector was created, the values of which represent a score given to the number of overlapping gaps in the motif: a score of 1 was assigned to 2 overlapping gaps, a score of 2 was assigned to three overlapping gaps, etc. The "gap overlap index" (GOI) was defined as the sum of the resulting vector scaled by the number of interneurons collected for that bird (divided by total interneuron count minus one). For statistical significance, we shuffled the position of the gaps within cells 1,000,000 times while maintaining their number and length and we established a GOI distribution that would be expected if the gaps were randomly distributed. The $p$-value was extracted based on the position of the experimental GOI in the shuffled distribution.

Retrograde labeling of projection neurons. For the in vitro slice experiments, $\mathrm{HVC}_{(\mathrm{RA})}$ neurons were labeled (see Fig. $4 A-C$ ) with a retrograde tracer (DiI) that was introduced $2-7 \mathrm{~d}$ before the preparation of acute brain slices (Daou et al., 2013). Under isoflurane anesthesia (1-3\% in oxygen), $45-50 \mathrm{~nL}$ of DiI (Invitrogen, $5 \mathrm{mg} / \mathrm{ml}$ in $\mathrm{N}, \mathrm{N}$-dimethylformamide) was injected into either RA or Area X at $4.6 \mathrm{nl} / \mathrm{min}$ using an oilbased pressure injection system (Nanoject II; Drummond Scientific). The craniotomy was then covered with a silicone elastomer (Kwik-Cast; WPI).

Slice preparation. All extracellular solutions were adjusted to 310 mOsm, pH 7.3-7.4, and aerated with a $95 \% / 5 \% \mathrm{O}_{2} / \mathrm{CO}_{2}$ mix. Zebra 


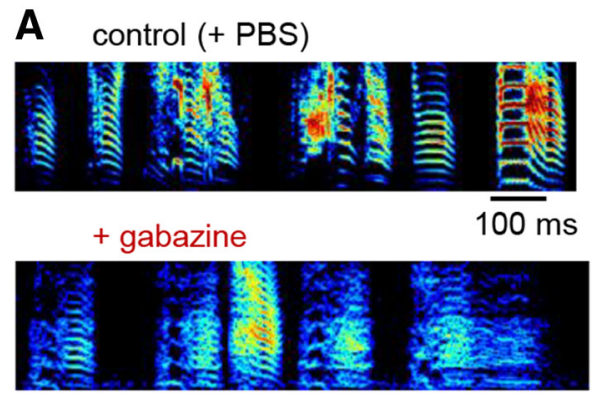

B

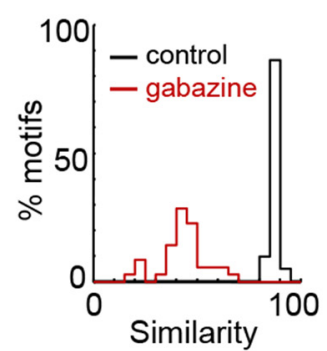

Figure 2. Inhibition is necessary for normal singing behavior. $\boldsymbol{A}$, Representative sonogram (range: $500-7500 \mathrm{~Hz}$ ) of a song motif after bilateral global infusion of PBS or gabazine into HVC. $\boldsymbol{B}$, Global similarity scores after gabazine infusion for the bird in $\boldsymbol{A}$. Shown are gabazine-control (red) and control-control (black) comparisons. $\boldsymbol{C}$, The mean song similarity for five birds (filled circles representing the bird highlighted to the left).

finches were first deeply anesthetized with an intramuscular injection of pentobarbital ( $40 \mathrm{mg} / \mathrm{kg}$ in saline). Once the animal was no longer responsive to a toe pinch, it was quickly decapitated and the brain was removed from the skull and submerged in cold $\left(1-4^{\circ} \mathrm{C}\right)$ oxygenated zero-sodium ACSF containing the following (in mM): 225 sucrose, $3 \mathrm{KCl}$, $1.25 \mathrm{NaH}_{2} \mathrm{PO}_{4}, 26 \mathrm{NaHCO}_{3}, 10 \mathrm{D}-(+)$-glucose, $\left.2 \mathrm{MgSO}_{4}, 2 \mathrm{CaCl}_{2}\right)$. The brain was then cut along the sagittal plane and the medial side of the right hemisphere was glued onto a custom-made slice block. The block was constructed such that the vibratome blade entered the brain posteriorly at a $12^{\circ}$ angle of elevation with respect to the glued medial side. Slices ( 300 $\mu \mathrm{m})$ containing HVC were produced using a vibratome (VT1200S; Leica) outfitted with a ceramic blade (Cadence) and an advancing speed of $0.12 \mathrm{~mm} / \mathrm{s}$. After cutting, slices were transferred to a recovery chamber with reduced sodium ACSF containing the following (in $\mathrm{mm}$ ): $60 \mathrm{NaCl}$, 75 sucrose, $2.5 \mathrm{KCl}, 1.2 \mathrm{NaH}_{2} \mathrm{PO}_{4}, 30 \mathrm{NaHCO}_{3}, 25 \mathrm{D}$-(+)-glucose, 20 HEPES, $2 \mathrm{MgSO}_{4}, 2 \mathrm{CaCl}_{2}$ ) at a temperature of $32^{\circ} \mathrm{C}$ for $25 \mathrm{~min}$. The slices remained in the recovery chamber for at least another $40 \mathrm{~min}$ at room temperature $\left(\sim 23^{\circ} \mathrm{C}\right)$ before electrophysiological recording.

Slice electrophysiological recording. Slices were constantly perfused in a submersion chamber with $35^{\circ} \mathrm{C}$ oxygenated recording ACSF containing the following (in mM): $126 \mathrm{NaCl}, 3 \mathrm{KCl}, 1.25 \mathrm{NaH}_{2} \mathrm{PO}_{4}, 26 \mathrm{NaHCO}_{3}, 10$ D-(+)-glucose, $2 \mathrm{MgSO}_{4}, 2 \mathrm{CaCl}_{2}$ at a rate of $>2.5 \mathrm{ml} / \mathrm{min}$. Patch pipettes were pulled to a final resistance of 3-7 $\mathrm{M} \Omega$ from filamented borosilicate glass on a Sutter P-97 horizontal puller and filled with internal solution containing the following (in mM): 0.2 EGTA, $130 \mathrm{~K}$-gluconate, $4 \mathrm{KCl}, 2$ $\mathrm{NaCl}, 10$ HEPES, 4 ATP-Mg, 0.3 GTP-Tris, 14 phosphocreatine-Tris and brought to $\mathrm{pH} 7.25$ and $292 \mathrm{mOsm}$. The liquid junction potential was measured to be $-15.1 \mathrm{mV}$, but this correction was not applied to the data presented here. In some experiments, $0.3 \%$ biocytin was added to the intracellular solution to enable neuronal reconstruction. Whole-cell recordings of up to four neurons simultaneously were amplified using two Axon Multiclamp 700B amplifiers (Molecular Devices), low-pass filtered at $10 \mathrm{kHz}$, sampled at $20 \mathrm{kHz}$ using an Axon Digidata 1440A (Molecular Devices), and acquired using pClamp 10.4 software (Molecular Devices).

Neuronal cell bodies were visualized for recording using an Axio Examiner A1 (Zeiss) fixed-stage upright microscope using IR-Dodt illumination through a $40 \times$ water-immersion objective. $\mathrm{HVC}_{(\mathrm{RA})}$ and $\mathrm{HVC}_{(\mathrm{X})}$ neurons were targeted under visual guidance by recording from DiIlabeled somata (see Fig. 4C-E) fluorescing in the red wavelength (575$640 \mathrm{~nm}$ ) using an Axiocam MRm fluorescence camera (Zeiss). Local HVC interneurons were targeted by selecting unlabeled neurons and verified to be interneurons based on their electrophysiological characteristics (Dutar et al., 1998; Kubota and Taniguchi, 1998) and the existence of inhibitory synaptic connections to other nearby neurons (see Figs. $4 D, E$, Fig. $5 D, F)$.

Recording quality was monitored throughout the experiment. Access resistance was compensated online and data were discarded if the resistance value increased $>30 \mathrm{M} \Omega$ or if the recorded neurons' resting membrane potential increased above $-45 \mathrm{mV}$. Monosynaptic and disynaptic inhibitory currents were measured in voltage-clamp configuration with the neuron clamped at $-46 \mathrm{mV}$ unless otherwise noted to increase the
C

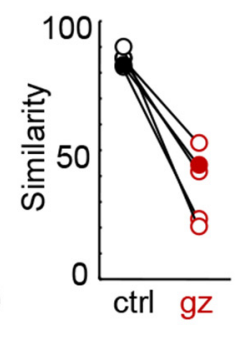

driving force for chloride relative to the RMP while retaining a stable baseline. $\mathrm{HVC}_{(\mathrm{RA})}$ neuron $\rightarrow$ interneuron monosynaptic excitatory currents were measured at the reversal potential for chloride $(-80 \mathrm{mV})$. Holding currents for current-clamp experiments and single-cell stimulation in paired recordings were injected manually and spikes were evoked by $2 \mathrm{~ms}$ square pulses of current injection $(0.8-1.8$ $\mathrm{nA})$. Typically, stimulation sweeps were given at $5 \mathrm{~s}$ intervals for $\sim 30$ repetitions.

For the functional experiments detailed in Figure 8, the L-type calcium channel agonist Bay $\mathrm{K} 8644(2.5 \mu \mathrm{M})$ was applied to the bath throughout the recording session to elicit in vivo-like bursts after somatic current injections (Long et al., 2010). To recruit the disynaptic pathway (see Fig. $8 A, B$ ), $\mathrm{HVC}_{(\mathrm{RA})}$ neuron axons were stimulated by placing a bipolar stimulating electrode (0.002-inch-diameter Teflon-insulated stainless steel wires positioned $\sim 75 \mu \mathrm{m}$ apart) on the visible fiber bundles coursing from HVC to RA using a stimulus isolator (AMPI). A custom stimulation protocol was designed to drive $\mathrm{HVC}_{(\mathrm{RA})}$ neurons to achieve an in vivolike firing pattern (see Fig. 3) in recorded HVC interneurons (Fig. 8C). This protocol ( $680 \mathrm{~ms}$ duration) consisted of trains and bursts of stimulations $(0.2 \mathrm{~ms}$ duration at 300 or $150 \mathrm{~Hz})$ and pauses of stimulation (65-100 ms). The protocol was kept constant for all recorded neurons and the same region of the stimulation protocol (65-75 ms pause flanked by $100 \mathrm{~ms}$ stimulation epochs at $150 \mathrm{~Hz}$ ) was used for $\mathrm{HVC}_{(\mathrm{RA})}$ neuron burst analysis. The current pulse administered to the $\mathrm{HVC}_{(\mathrm{RA})}$ neurons had a duration of $35 \mathrm{~ms}$ and the rheobase and spiking characteristics were determined by increasing the current pulse in $25 \mathrm{pA}$ steps.

Determining pair distance and orientation. Slices containing HVC were placed in the recording chamber with either the medial or the lateral side facing up. The reference angle of HVC was taken across the widest part of HVC in the slice, easily visible under a $2.5 \times$ objective. Neuron pairs were targeted at random locations and angles within HVC, but with a minimum depth of $\sim 50 \mu \mathrm{m}$. The distance between pairs of neurons was measured while recording from the somatic centers of the two neurons. Images were taken using an infrared camera (DAGE-MTI IR-1000) connected to a monitor and frame grabber card (dPict Imaging) on a computer. Angles between pairs of neurons were calculated with respect to the reference angle of HVC (anterior-posterior axis) offline using image analysis software (ImageJ). Neurons were generally targeted for recording if they were not farther than $100 \mu \mathrm{m}$ apart. Depth differences between recorded neurons were taken into account in calculating the distance between somata, but they were generally not large (average $=0.32 \pm 7.62$ $\mu \mathrm{m})$.

Morphological reconstruction. Slices containing biocytin-filled neurons were placed in $4 \%$ PFA (EMS) in $0.1 \mathrm{M}$ PBS after recording and fixed overnight. Slices were then placed in $30 \%$ sucrose in $0.1 \mathrm{M}$ PBS and, after $>24 \mathrm{~h}$ of storage, permeabilized by shock freezing in liquid nitrogen (for $5-10 \mathrm{~s}$ ) and subsequently washed in $0.4 \%$ Triton X-100 (Sigma) in $0.1 \mathrm{M}$ PBS. Slices were then incubated in 1:750 streptavidin Alexa Fluor 488 conjugate (Invitrogen) in $0.1 \mathrm{M}$ PBS for $24 \mathrm{~h}$ and washed with multiple rinses of $0.1 \mathrm{M}$ PBS over 1-2 d before being mounted on microscope slides (Fisher Scientific) using fluorescent mounting medium (Vector Labs). High resolution $z$-projection images of the filled neurons were taken using a Zeiss 510 LSM confocal microscope with a $40 \times$ Plan-Neo/1.3 numerical aperture oil objective and ZEN pro software. Neurons were reconstructed offline by using Neurolucida version 9.14.5.

In vitro data analysis. Spike shape, synaptic delays, and connection strengths were quantified using Clampfit 10.4 (Molecular Devices). Spike width was determined at half-height from threshold. Synaptic delays (monosynaptic and disynaptic) were estimated from the peak of the presynaptic spike to the onset of the evoked postsynaptic current. Stimulation-evoked delays (monosynaptic and disynaptic) were calculated from the onset of the stimulation artifact to the onset to the evoked postsynaptic current. Synaptically evoked current amplitudes were mea- 
sured at the peak of the response with respect to the baseline preceding the stimulation. Average traces and synaptic strength values shown are created from at least 10 sweeps of raw traces. In $\mathrm{HVC}_{(\mathrm{RA})}$ neuron pairs used to investigate frequency dependence of the disynaptic IPSC, success rate was quantified as the ratio of trials (at $300 \mathrm{~Hz}$ presynaptic stimulation), which evoked a disynaptic IPSC of the total number of trials. We used the Rayleigh tests on connectivity data (Circular Statistics Toolbox) (Berens, 2009) to ensure that the entire range of angular positions are randomly sampled. $\mathrm{Di}$ rectional bias of disynaptic IPSC strength coupling in the $\mathrm{HVC}_{(\mathrm{RA})}$ neuron network was calculated from the average disynaptic connection strengths with their respective orientations (soma to soma within HVC). The average radial strength was extracted from the data by linear interpolation into 1 degree bins and subsequent smoothing using a 30 degree rectangular window (see Fig. $6 F$ ). The bimodal directional bias was computed by examining the axis that had the largest ratio from one radial angle to its orthogonal axis. A one-sided permutation test was performed by shuffling these original strength and angle values one million times and computing the largest resultant ratio for each instance.

\section{Results}

Our first step was to test the model in which inhibition is not involved in the generation of song-related HVC sequences (Fig. 1B). In this view, patterned excitation from highly specific excitatory connectivity is sufficient to generate HVC premotor patterns. One prediction from this idea is that the pharmacological manipulation of inhibitory conductances should not affect singing behavior. In five zebra finches, we examined changes to song quality after bilateral infusion of the $\mathrm{GABA}_{\mathrm{A}}$ antagonist gabazine (0.015-0.025 $\mathrm{mm}$ ) into HVC. In all cases, blocking HVC inhibition led to a degradation in song structure (Fig. 2A-C), which can be observed as a significant decrease in global similarity compared with control values $(p<0.002$, paired $t$ test). Often, singing behavior was completely eliminated after $30-60 \mathrm{~min}$ in the presence of gabazine. This observation rules out the idea that HVC sequences are generated in the absence of synaptic inhibition (Fig. 1B).

The remaining models outlined above (Fig. 1) make different predictions concerning the song-related firing pattern of inhibitory interneurons. To address this issue directly, we recorded from 29 interneurons (15 intracellular, 14 juxtacellular) from 9 birds during singing (Fig. 3).

Consistent with previous reports ( $\mathrm{Yu}$ and Margoliash, 1996; Hahnloser et al., 2002; Kozhevnikov and Fee, 2007; Amador et al., 2013; Guitchounts et al., 2013), single interneurons often exhibited structured spiking during singing, with local minima in their

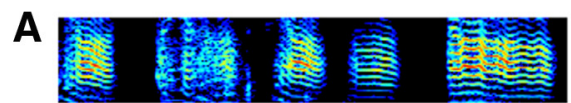

Interneuron

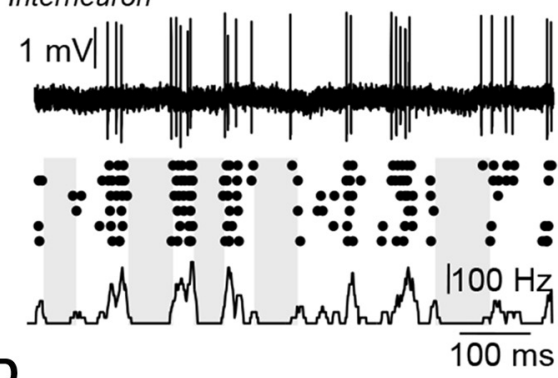

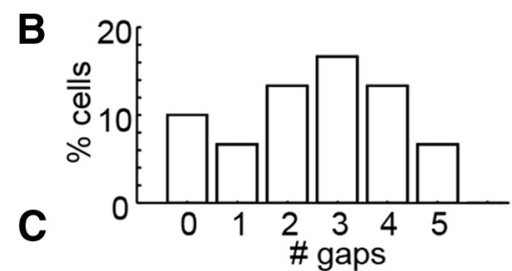

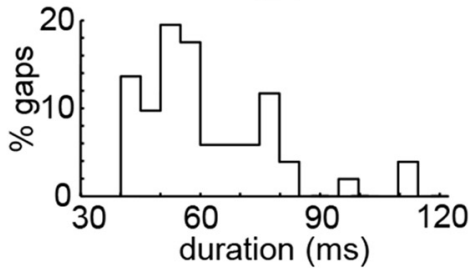

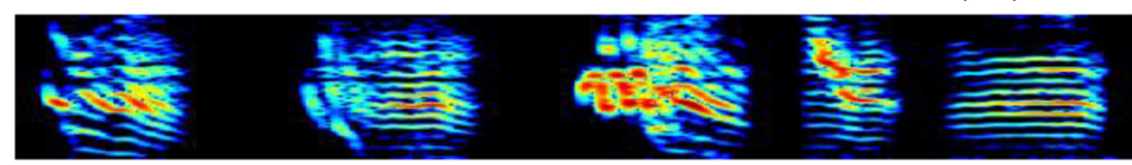
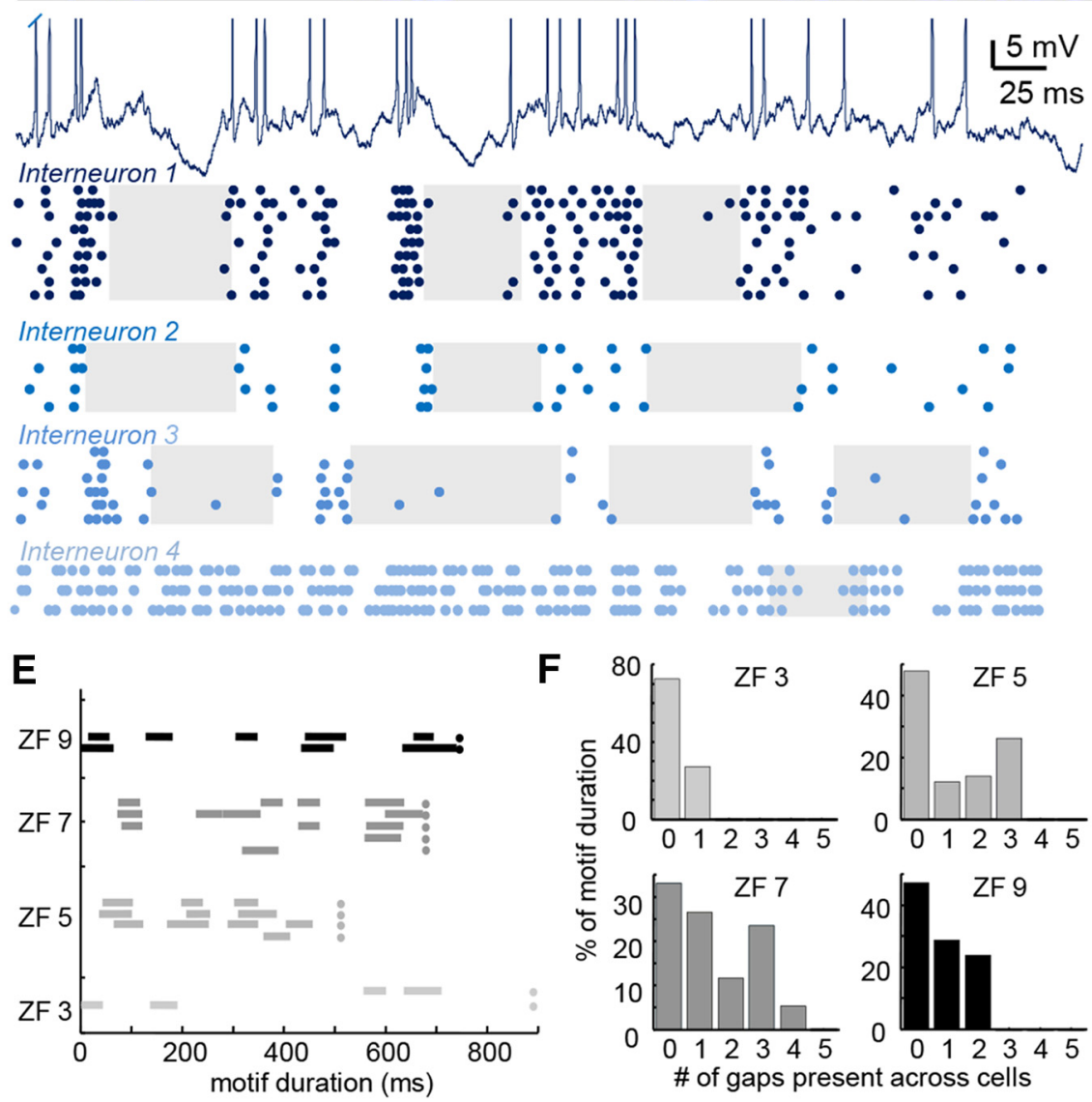

Figure 3. Coherent gaps in HVC interneuron spiking activity during singing. $A$, Example juxtacellular recording from an interneuron during singing along with a dot raster plot showing precise temporal structure across six song motifs. The mean firing rate is described in the plot below and gaps are designated with shaded rectangles in the raster plot. $B, C$, Histograms showing the number of gaps per song motif $(\boldsymbol{B})$ as well as the duration of gaps $(\boldsymbol{C})$ across a population of $19 \mathrm{HVC}$ interneurons. $\boldsymbol{D}$, Example intracellular recording from an interneuron during singing and a raster plot showing the spike times of that neuron across nine song motifs (in dark blue) as well as three additional interneurons (shades of blue) recorded from the same electrode track in one bird. $\boldsymbol{E}$, Gaps in the firing of different interneurons during song production are indicated by lines $(n=13$ interneurons in 4 birds). Cells from each bird are recorded within a single electrode track. Dots symbolize the end of the motif. $\boldsymbol{F}$, Occurrence of inhibitory gaps (plotted as percentage of total motif duration) for the population of interneurons shown in $E$. A value of 0 indicates a lack of gaps across the population and a value of 1 indicates only one gap occurring at a particular time. Values of 2 or more indicate simultaneously occurring gaps.

spike rates (Amador et al., 2013) that resemble the inhibitory pauses or gaps observed in a variety of other neural circuits (Deniau and Chevalier, 1985; Wilent and Nitz, 2007). We examined cases for which we recorded at least three song motifs $(n=19$ 

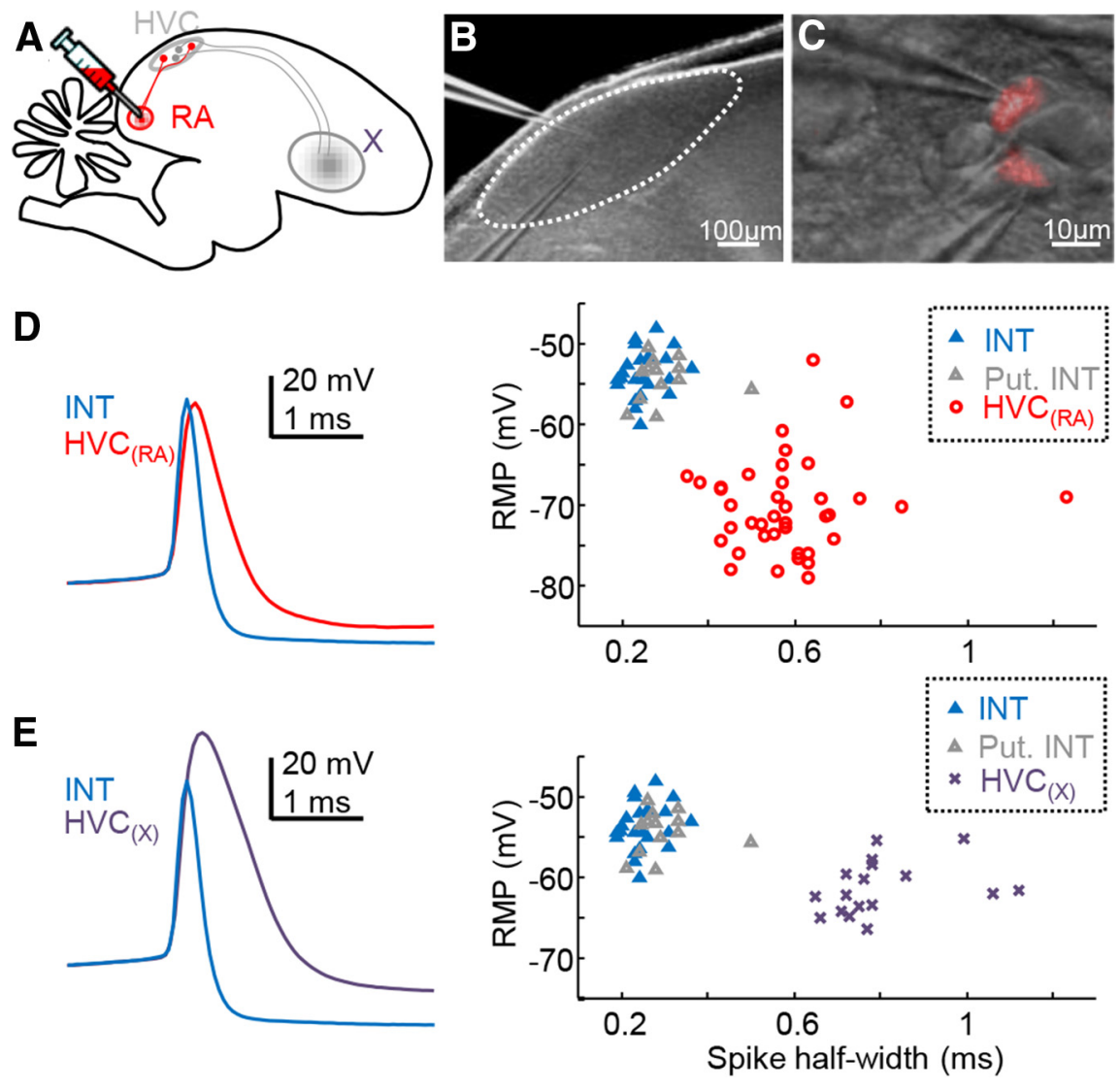

Figure 4. Classification of HVC cell types in vitro. $\boldsymbol{A}$, Schematized parasagittal section through the zebra finch brain, showing a

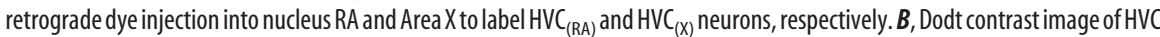

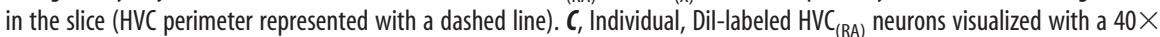
objective (red overlay of fluorescence image) and targeted with whole-cell patch pipettes. $D$, HVC interneurons frequently formed inhibitory synaptic connections onto nearby cells (see Fig. 5 for an example), confirming their identity (blue triangles, $n=22$ pairs). Otherwise, putative HVC interneurons (gray triangles, $n=13$ cells) were classified based on their intrinsic properties, namely spike waveform (overlay on left) and RMP, which were distinct from a set of retrogradely labeled HVC $\mathrm{CRA}_{\text {(R) }}$ neurons ( $n=39$ cells). $\boldsymbol{E}$, Putative HVC interneurons were also separable from a set of retrogradely labeled $\mathrm{HVC}_{(\mathrm{X})}$ neurons $(n=17$ cells). On average, the RMP of $\mathrm{HVC}_{(\mathrm{RA})}$ neurons, $\mathrm{HVC}_{(\mathrm{X})}$ neurons, and $\mathrm{HVC}$ interneurons were $-70.37 \pm 5.70 \mathrm{mV},-61.35 \pm 3.27 \mathrm{mV}$, and $-53.97 \pm 2.80 \mathrm{mV}$, respectively. Spike half-width of these three major HVC cell classes were also different across these groups $\left(\mathrm{HVC}_{(\mathrm{RA})}: 0.58 \pm 0.15 \mathrm{~ms}, \mathrm{HVC}_{(\mathrm{X})}: 0.80 \pm 0.13 \mathrm{~ms}\right.$, interneuron: $\left.0.27 \pm 0.06 \mathrm{~ms}\right)$.

cells) and defined a gap as a period of time in which interneuron firing was consistently suppressed across trials (Fig. $3 A$, see Materials and Methods for details). Interneuron gaps occurred frequently during singing (Fig. 3B, $2.6 \pm 1.6$ gaps/motif) with an average duration of $62 \pm 13 \mathrm{~ms}$ (Fig. $3 C$ ). We reasoned that inhibitory gaps, if aligned across multiple interneurons, could strongly modulate the activity of postsynaptic neurons, permitting them to burst at a specific time. To begin to investigate this idea, we examined 4 cases in which we recorded multiple interneurons (mean $=3.25$ cells/bird) along the same electrode track within HVC of a single bird. Inhibitory gaps were significantly aligned (Fig. 3D-F) in three of these cases (ZF 9, ZF 7, and ZF $5)$, showing a GOI (see Materials and Methods for details) of 178 $(p=0.020), 131(p=0.0037)$, and $113(p<0.0001)$, respectively, whereas inhibitory gaps within one case did not show a significant overlap (GOI $=0, p=0.49$ ). Our data show clear temporal coherence within the gaps in firing exhibited by nearby inhibitory neurons, which is highly suggestive that structured inhibition may be playing a prominent role in shaping the fine timing of $\mathrm{HVC}_{(\mathrm{RA})}$ activity (Fig. 1D,E).

We next wanted to examine the synaptic interactions between inhibitory interneurons and $\mathrm{HVC}_{(\mathrm{RA})}$ neurons directly to assess
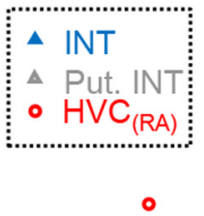

the potential effect of coherent inhibition within the HVC premotor network (Fig. 3). The other primary projection cell type within $\mathrm{HVC}\left(\mathrm{HVC}_{(\mathrm{X})}\right.$ neurons) formed infrequent synaptic connections onto $\mathrm{HVC}_{(\mathrm{RA})}$ neurons (Mooney and Prather, 2005) and were not investigated further in this study. Previous paired recordings demonstrated direct monosynaptic connections between $\mathrm{HVC}_{(\mathrm{RA})}$ neurons and interneurons (Mooney and Prather, 2005). To better characterize the incidence and strength of these interconnections, we performed multiple simultaneous wholecell recordings from identified $\mathrm{HVC}_{(\mathrm{RA})}$ neurons (Fig. 4A-C) and interneurons (Fig. 4D, E, see Materials and Methods for cell identification) in a slice preparation (69 slices from 49 adult zebra finches). We found that $\mathrm{HVC}_{(\mathrm{RA})}$ neurons formed monosynaptic connections onto interneurons (Fig. $5 \mathrm{~A}, \mathrm{C}$ ) with a probability of 0.79 and HVC interneurons inhibited $\mathrm{HVC}_{(\mathrm{RA})}$ neurons directly (Fig. 5B,D) with a probability of 0.67 (Table 1 ). These findings show a considerably more highly interconnected network than previous estimates, where $\mathrm{HVC}_{(\mathrm{RA})}$-interneuron monosynaptic projections were measured in $<20 \%$ of cases (one connection of each type for the six pairs reported; Mooney and Prather, 2005). In addition, we used voltage-clamp recordings to measure average unitary synaptic current strength within the $\mathrm{HVC}_{(\mathrm{RA})}$ - interneuron network (Fig. 5C-F, Table 1), which was found to not be dependent on intersomatic distance (Fig. $5 E, F, p>0.5$, Spearman's correlation coefficient).

Given the widespread recurrent connectivity between $\mathrm{HVC}_{(\mathrm{RA})}$ neurons and interneurons, we reasoned that $\mathrm{HVC}_{(\mathrm{RA})}$ neuron spiking may be sufficient to drive structured activity in the interneuron network. To address this, we injected high-frequency $(300 \mathrm{~Hz})$ current steps into $\mathrm{HVC}_{(\mathrm{RA})}$ neurons to simulate the bursting activity that had been observed previously during singing (Hahnloser et al., 2002; Long et al., 2010; see also Fig. 7D). We found that in vivolike bursting activity was capable of eliciting spikes across all $\mathrm{HVC}_{(\mathrm{RA})} \rightarrow$ interneuron pairs we tested $(n=7)$ with an average reliability of $75.4 \pm 25.7 \%$, whereas single $\mathrm{HVC}_{(\mathrm{RA})}$ spikes were much less likely to do so ( 1 of 7 pairs; Fig. $5 G, H$ ). We attribute this frequency dependence to synaptic facilitation (Mooney and Prather, 2005; Fig. 5I), which occurred in 17 of $19 \mathrm{HVC}_{(\mathrm{RA})} \rightarrow$ interneuron pairs ( $\mathrm{EPSC}_{2} / \mathrm{EPSC}_{1}=1.74 \pm 0.97$ ). In subsequent triple recordings, we found that a single $\mathrm{HVC}_{(\mathrm{RA})}$ burst could reliably align spikes in multiple interneurons recorded simultaneously (Fig. 5J). We can conclude that the high-frequency bursting activity produced by $\mathrm{HVC}_{(\mathrm{RA})}$ neurons during singing is able to modulate the firing pattern of HVC interneurons significantly.

Because an $\mathrm{HVC}_{(\mathrm{RA})}$ burst could activate an interneuron network (Fig. $5 H, J)$ that in turn broadly inhibits other $\mathrm{HVC}_{(\mathrm{RA})}$ neurons (Fig. $5 D, F$ ), we reasoned that a single $\mathrm{HVC}_{(\mathrm{RA})}$ burst 
A
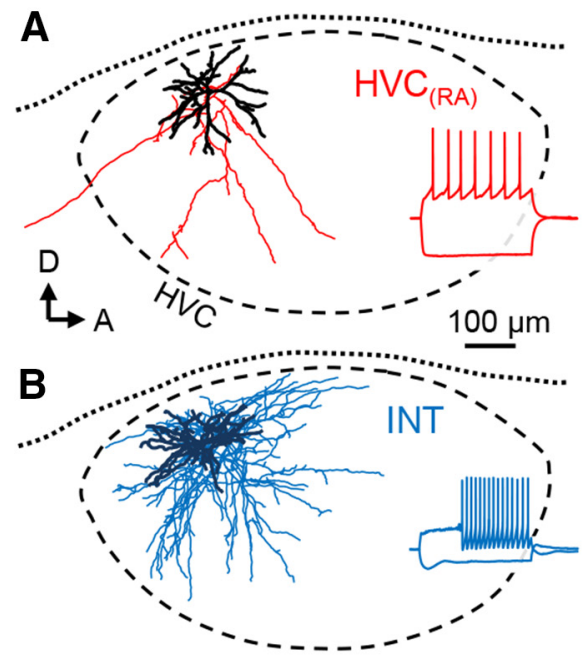
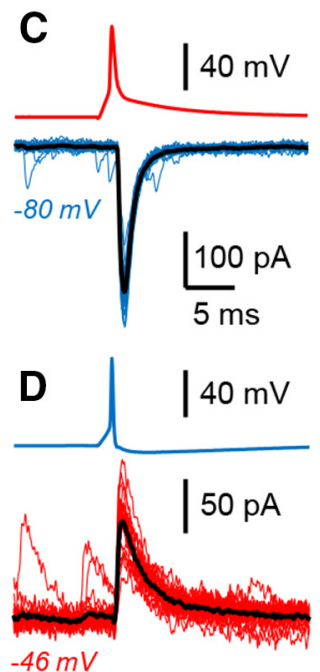

$-46 m V$

G
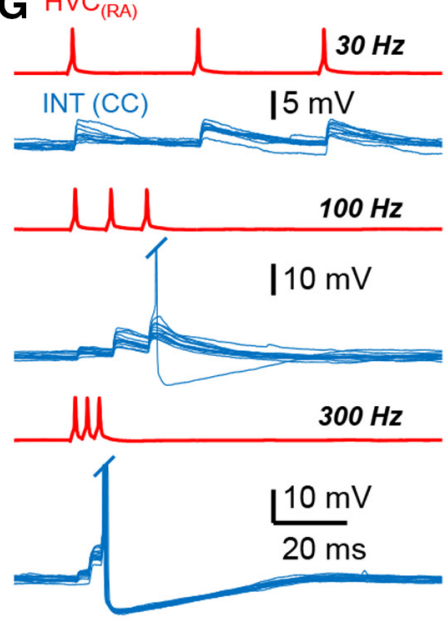

H

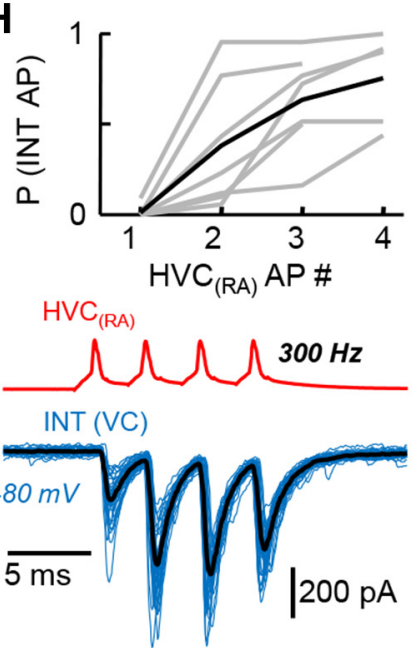

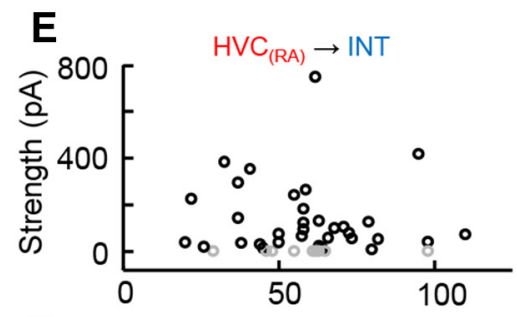

F

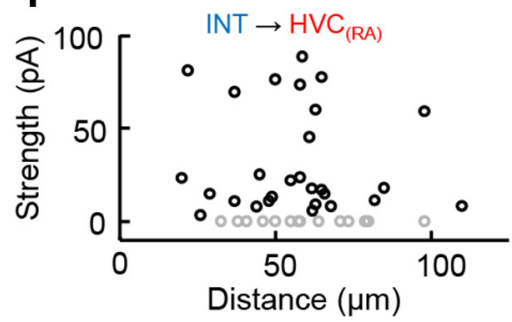

J

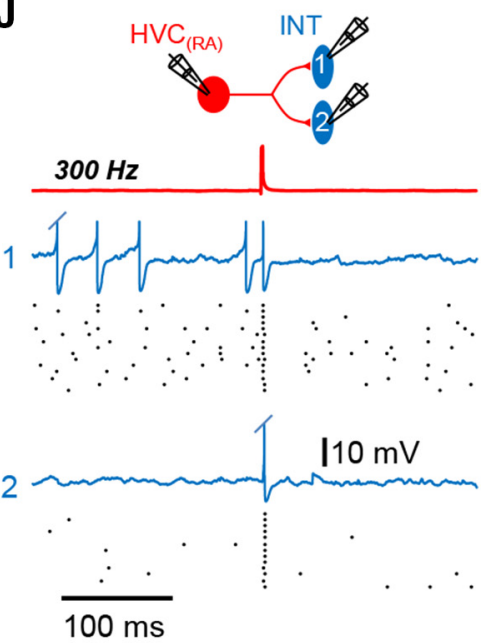

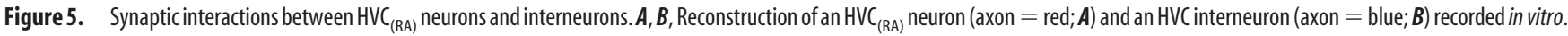
Inset are responses of these cells to hyperpolarizing $(-400 \mathrm{pA})$ and depolarizing current steps $\left(\mathrm{HVC}_{(\mathrm{RA})}: 200 \mathrm{pA}\right.$, interneuron: $\left.400 \mathrm{pA}\right)$. $\boldsymbol{C}, \boldsymbol{D}$, Reciprocal synaptic connectivity between the neurons shown in $\boldsymbol{A}$ and $\boldsymbol{B}$ (black trace $=$ average response). $\boldsymbol{E}, \boldsymbol{F}$, Synaptic strength of all recorded $\mathrm{HVC}_{(\mathrm{RA})} \rightarrow$ interneuron $(\boldsymbol{E})$ and interneuron $\rightarrow H V C_{(\mathrm{RA})}(\boldsymbol{F})$ connections with respect to intersomatic distance (gray is nonconnected). $\mathbf{G}$, Frequency dependence of the $\mathrm{HVC}_{(\mathrm{RA})} \rightarrow$ interneuron connections showing that a $300 \mathrm{~Hz}$ HVC $\mathrm{C}_{(\mathrm{RA})}$ burst activates a postsynaptic interneuron (RMP $=-54.5 \mathrm{mV}$ ). $\boldsymbol{H}, \mathrm{An} \mathrm{HVC}_{(\mathrm{RA})}$ burst often produces a reliable spike in postsynaptic interneurons (7 pairs, average in black). I, A typical HVC $\mathrm{H}_{(\mathrm{RA})} \rightarrow$ interneuron pair in which facilitating EPSCs can be visualized using voltage-clamp. J, Triplet recording from one $\mathrm{HVC}_{(\mathrm{RA})}$ neuron connected to two interneurons, as shown by the schematic on top. A single $300 \mathrm{~Hz}$ burst ( 3 spikes) in the $\mathrm{HVC}_{(\mathrm{RA})}$ neuron (red trace) was able to reliably evoke synchronous spiking in two postsynaptic interneurons (blue $=$ example traces, black $=$ raster plots from 15 trials).

Table 1. Synaptic connections between $\mathrm{HVC}_{(\mathrm{RA})}$ neurons and interneurons

\begin{tabular}{lccl}
\hline Connection tested & Incidence & $\begin{array}{l}\text { Synaptic } \\
\text { strength }(\mathrm{pA})\end{array}$ & $\begin{array}{l}\text { Delay time } \\
(\mathrm{ms})\end{array}$ \\
\hline $\mathrm{HVC}_{(\mathrm{RA})} \rightarrow \mathrm{INT}(\mathrm{E}, m)$ & $34 / 43$ & $135.6 \pm 155.8$ & $0.43 \pm 0.16$ \\
$\mathrm{INT} \rightarrow \mathrm{HVC}_{(\mathrm{RA})}(\mathrm{l}, m)$ & $28 / 42$ & $31.8 \pm 28.0$ & $0.37 \pm 0.10$ \\
$\mathrm{HVC}_{(\mathrm{RA})} \rightarrow \mathrm{HVC}_{(\mathrm{RA})}(\mathrm{E}, m)$ & $1 / 140$ & 22.8 & 1.01 \\
$\mathrm{HVC}_{(\mathrm{RA})} \rightarrow \mathrm{HVC}_{(\mathrm{RA})}(\mathrm{I}, d)$ & $78 / 140$ & $25.2 \pm 23.8$ & $1.85 \pm 0.30$
\end{tabular}

Values for incidence, average synaptic strength measured in voltage clamp, and delay times are shown for all paired recordings. The type of connection is shown on the right in the first column: E, Excitatory; I, inhibitory; $m$, monosynaptic; $d$, disynaptic.

may widely affect the HVC circuit through disynaptic inhibition, a phenomenon often observed between pyramidal neurons of mammalian neocortex (Kapfer et al., 2007; Silberberg and Markram, 2007; Fino and Yuste, 2011). Using multiple simultaneous recordings, we assayed the properties of disynaptic inhibition between $\mathrm{HVC}_{(\mathrm{RA})}$ neurons. In one triple recording, we confirmed the involvement of an HVC interneuron directly in the disynaptic inhibition observed between two $\mathrm{HVC}_{(\mathrm{RA})}$ neu- rons (Fig. 6A). Across $9 \mathrm{HVC}_{(\mathrm{RA})}$ pairs, the average evoked disynaptic IPSC strength increased from $1.5 \pm 0.4 \mathrm{pA}$ to $41.4 \pm 20.9$ pA $(p<0.001$, paired $t$ test $)$ as the presynaptic intraburst spike rate was raised from 30 to $300 \mathrm{~Hz}$ (Fig. 6B), which led to a highly reliable (success rate $=0.904$ ) and rapid (Fig. $6 C$, Table 1 ) disynaptic response. At a population level, we found that a single HV$\mathrm{C}_{(\mathrm{RA})}$ presynaptic burst caused disynaptic inhibition with a probability of 0.557 . The strength of the resultant inhibitory current (Table 1 ) was independent of intersomatic distance $(p=$ 0.484 , Spearman's correlation coefficient; mean distance $=$ $58.2 \pm 32.9 \mu \mathrm{m}$, range $4-178 \mu \mathrm{m})$. Disynaptically connected pairs were then examined with respect to their relative angular position within HVC (Fig. 6D). Surprisingly, we found that both the incidence and strength of disynaptic inhibition was biased in an approximately anterior-posterior fashion $(p=0.024$, Rayleigh test and $p=0.033$, permutation test, respectively; Fig. $6 E, F)$, which is consistent with previous anatomical findings demonstrating spatial anisotropies within HVC (Nottebohm et al., 1982; Poole et al., 2012; Stauffer et al., 2012). 

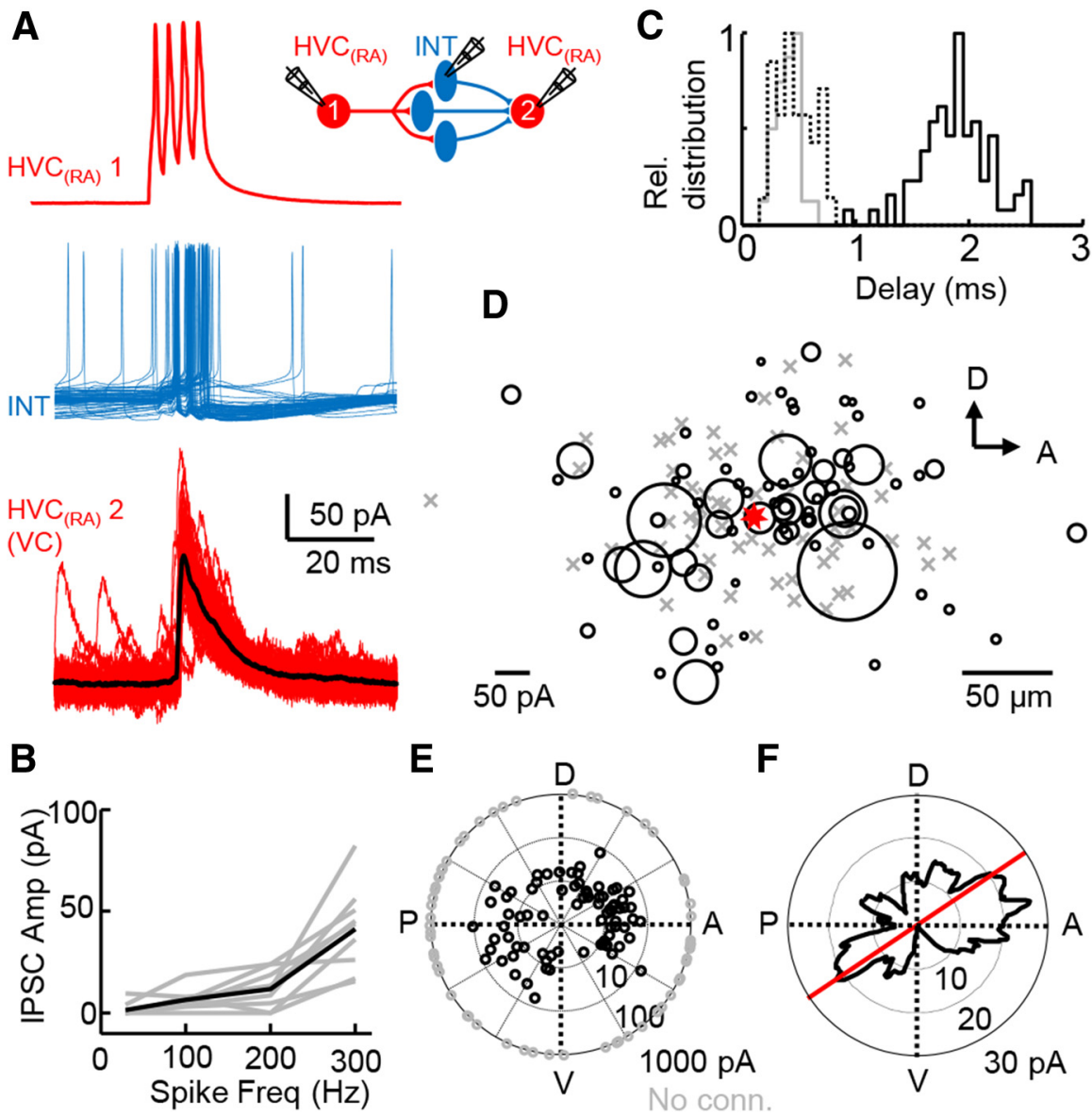

Figure 6. Prominent disynaptic inhibition between $\mathrm{HVC}_{(\mathrm{RA})}$ neurons. $A$, Schematic and recording of two $\mathrm{HVC}_{(\mathrm{RA})}$ neurons and an intermediate interneuron. An evoked high-frequency burst (4 spikes at $300 \mathrm{~Hz}$ ) in one $\mathrm{HVC}_{(\mathrm{RA})}$ neuron typically elicits an action potential in an interneuron (RMP $=-54.4 \mathrm{mV}$ ) and subsequent inhibitory responses in another $\mathrm{HVC}_{(\mathrm{RA})}$ cell. $B, \mathrm{HVC}_{(\mathrm{RA})}$ neuron pairs often exhibit frequency-dependent disynaptic inhibition quantified across a population of 9 pairs (average in black). $\boldsymbol{C}$, Distribution of delay times for all connections (disynaptic $\mathrm{HVC}_{(\mathrm{RA})} \rightarrow \mathrm{HVC}_{(\mathrm{RA})}$, black line; monosynaptic $\mathrm{HVC}_{(\mathrm{RA})} \rightarrow$ interneuron, dotted line; monosynaptic interneuron $\rightarrow \mathrm{HVC}_{(\mathrm{RA})}$ connections, gray line). D, $\mathrm{HVC}_{(\mathrm{RA})} \rightarrow \mathrm{HVC}_{(\mathrm{RA})}$ disynaptic inhibitory connections plotted with respect to their position in the parasagittal plane (red is presynaptic cell; size of black circles show strength of inhibitory connection; gray Xs are not connected). $\boldsymbol{E}_{,} \mathrm{HVC}_{(\mathrm{RA})} \rightarrow \mathrm{HVC}_{(\mathrm{RA})}$ disynaptic IPSC strengths $(n=140$ pairs) also plotted with their relative directionality within HVC. We sampled uniformly from all angular positions in the parasagittal plane of HVC ( $p=$ 0.428, Rayleigh test). $\boldsymbol{F}$, Smoothed average of IPSC strength values from $\boldsymbol{C}$, including nonconnected as 0 pA strength (see Materials and Methods for details). Red line ( $34^{\circ}$ ventral deviation from anterior $\rightarrow$ posterior axis of HVC) shows the largest bimodal bias of disynaptic IPSC strength coupling between pairs of $\mathrm{HVC}_{(\mathrm{RA})}$ neurons.

In addition to the disynaptic inhibitory connections observed between $\mathrm{HVC}_{(\mathrm{RA})}$ neurons, we also found only one $\mathrm{HVC}_{(\mathrm{RA})}-$ $\mathrm{HVC}_{(\mathrm{RA})}$ excitatory synapse, a connection probability of 0.007 (Table 1 ). Because a single $\mathrm{HVC}_{(\mathrm{RA})}$ burst was nearly 80 times more likely to result in an IPSC than an EPSC in another $\mathrm{HVC}_{(\mathrm{RA})}$ neuron, we considered the possibility that structured inhibition alone may be sufficient to generate HVC premotor patterning. In this view, gaps within inhibitory interneuron firing can act as a filter for constant external excitatory input onto $\mathrm{HVC}_{(\mathrm{RA})}$ neurons (Fig. 1E). Short gaps in inhibition should appear as depolarizing potentials and longer gaps could allow the neuron to cross a threshold for producing a burst. This model is consistent with a recent "winnerless competition" simulation in which inhibitory connectivity could activate premotor neurons precisely within HVC (Yildiz and Kiebel, 2011).

To test the idea that structured inhibition alone could result in HVC sequence generation, we needed a method to alter inhibition specifically onto our recorded neuron in the context of normal singing behavior. If patterned inhibition is necessary to produce depolarizing postsynaptic potentials and precisely timed burst events, then decreasing inhibition onto recorded $\mathrm{HVC}_{(\mathrm{RA})}$ neurons should disrupt postsynaptic potentials and cause spike timing to become more variable. To test this idea, we introduced gabazine to a single spatially restricted region of HVC on one hemisphere (see Materials and Methods for details). Local gabazine microinfusions had a minor, but not statistically significant ( $p=0.16$, paired $t$ test), effect on singing behavior (Fig. $7 A-C$ ). We then recorded the membrane potential of 23 $\mathrm{HVC}_{(\mathrm{RA})}$ neurons in four freely behaving zebra finches during singing in the presence of gabazine (Fig. $7 D, E$ ), including cases in which a within-neuron comparison of activity before and after gabazine treatment was collected (Fig. 7D). After gabazine treatment, we observed the conversion of postsynaptic events into spiking responses. To quantify the effect of decreasing inhibition on our entire dataset, we compared the gabazine-treated $\mathrm{HVC}_{(\mathrm{RA})}$ neurons with a population of untreated $\mathrm{HVC}_{(\mathrm{RA})}$ controls $(n=27$ cells from 8 birds). Across the population, gabazine infusion resulted in an increase in the number of action potentials $(p=$ 0.013, control: $3.6 \pm 4.1$, gabazine: $7.1 \pm$ 6.5 ) and burst events ( $p=0.0053$, control: $0.7 \pm 0.6$, gabazine: $1.6 \pm 1.4$ ) per motif. The frequency of spikes within a burst ( $p=0.090$, control: $512.9 \pm 305.5$ $\mathrm{Hz}$, gabazine: $391.5 \pm 170.6 \mathrm{~Hz})$, the number of spikes within a burst $(p=0.87$, control: $4.2 \pm 2.6$, gabazine: $3.9 \pm 1.9$ ) and the number of single spikes observed within the motif ( $p=0.94$, control: $0.6 \pm$ 1.0 , gabazine: $0.7 \pm 1.4)$ were not significantly affected. Importantly, the timing of the bursts did not differ after gabazine infusion $(p=0.33$, rms jitter $=1.6 \pm 1.1 \mathrm{~ms}$ for control and $2.0 \pm 1.3 \mathrm{~ms}$ for gabazine), which directly contradicts the model in which inhibition alone is sufficient to enable HVC sequence generation (Fig. 1E).

To this point, our experiments had strongly suggested that time-varying excitation and inhibition underlie the generation of HVC premotor sequences. To establish the feasibility of this idea, we sought to perform functional experiments in which we could imitate in vivo HVC interneuron firing patterns (Fig. 3) within our slice preparation. It had been shown previously that stimulation of the $\mathrm{HVC} \rightarrow \mathrm{RA}$ pathway can strongly excite local interneurons through excitatory collaterals from antidromically activated $\mathrm{HVC}_{(\mathrm{RA})}$ neurons (Hahnloser et al., 2006; Fig. 8A,B). In $11 \mathrm{HV}$ $\mathrm{C}_{(\mathrm{RA})}$ cells ( 5 birds), we stimulated the $\mathrm{HVC} \rightarrow \mathrm{RA}$ fiber tract with an extracellular electrode (range: $12-60 \mu \mathrm{A}$, mean $=42.5 \mu \mathrm{A}$, see Materials and Methods for details), which led to reliable and structured spiking activity in HVC interneurons (Fig. 8C) and disynaptic inhibition in $\mathrm{HVC}_{(\mathrm{RA})}$ neurons (Fig. $8 A, B, D$ ). In separate voltage-clamp experiments, the strength of IPSCs recorded was on average $336.7 \pm 139.2 \mathrm{pA}(n=9$; Fig. $8 B)$, corresponding 
to activating $\sim 10-15$ interneurons connected to the recorded $\mathrm{HVC}_{(\mathrm{RA})}$ neuron. Direct excitatory currents evoked by this stimulation only occurred in 3 cases (Fig. $8 A, B)$, indicating that the majority of stimulation evoked currents were inhibitory and confirming sparse excitatory connectivity between $\mathrm{HVC}_{(\mathrm{RA})}$ neurons (Table 1).

We then wanted to recapitulate the allor-none bursts seen in $\mathrm{HVC}_{(\mathrm{RA})}$ neurons in vivo in the context of patterned inhibition. Because $\mathrm{HVC}_{(\mathrm{RA})}$ neurons do not fire bursts after somatic current injection (Dutar et al., 1998; Mooney, 2000), we bath-applied the L-type calcium channel agonist Bay K8644 (2.5 $\mu \mathrm{M})$, which we have previously shown can enable an allor-none response in vitro (Long et al., 2010). Each recorded $\mathrm{HVC}_{(\mathrm{RA})}$ neuron was held with $167 \pm 99 \mathrm{pA}$ somatic current injection to achieve a stable membrane potential of $-48.2 \pm 2.4 \mathrm{mV}$ ( -63 $\mathrm{mV}$ with liquid junction potential correction), which is similar to the steady depolarization observed during singing (Long et al., 2010). All-or-none bursts could be evoked by the injection of an additional brief current pulse into the soma (Fig. $8 E, H$, rheobase value: $150 \pm 39 \mathrm{pA}$, $n=11$ cells) only if this pulse was timed to precisely intersect with a gap in disynaptic inhibition. If the same current pulse was given during ongoing inhibition, no spikes were evoked (Fig. $8 F$ ). Significantly increasing current amplitude to the $\mathrm{HVC}_{(\mathrm{RA})}$ neuron during inhibition led to the appearance of action potentials (Fig. $8 G$, rheobase value $=266 \pm 82 \mathrm{pA}, n=11$ cells), which grew in number gradually as the current amplitude increased (Fig. 8I). These results suggest that the disynaptic pathway can have a strong shunting effect capable of preventing allor-none burst-inducing currents from occurring (Murayama et al., 2009). Together, these data indicate that the initiation of song-related bursting activity and the resultant population sequence is likely to require the coincidence of an excitatory drive with a pause in synaptic inhibition (Fig. 1D).

\section{Discussion}

In this study, we investigated the synaptic mechanisms underlying the generation of premotor sequences within HVC of the zebra finch. We used a variety of techniques to address experimentally previously proposed models of HVC function (Fig. 1) and several lines of evidence support the idea that patterned inhibitory and excitatory currents are needed to drive song-related HVC sequences (Fig. 1D). First, we established that inhibition is necessary for HVC sequence generation after observing a degradation of singing behavior after the pharmacological blockade of $\mathrm{GABA}_{\mathrm{A}}$ conductances in HVC. Second, interneurons show clear gaps in their firing during singing that are often aligned across closely spaced neurons. Third, the interconnections between inhibitory and excitatory neurons are more than four times greater than previously estimated (Mooney and Prather, 2005), leading to a disynaptic pathway capable of strongly modulating interneuron activity and broadly inhibiting other $\mathrm{HVC}_{(\mathrm{RA})}$ neurons. Together, our data strongly suggest that structured inhibition and
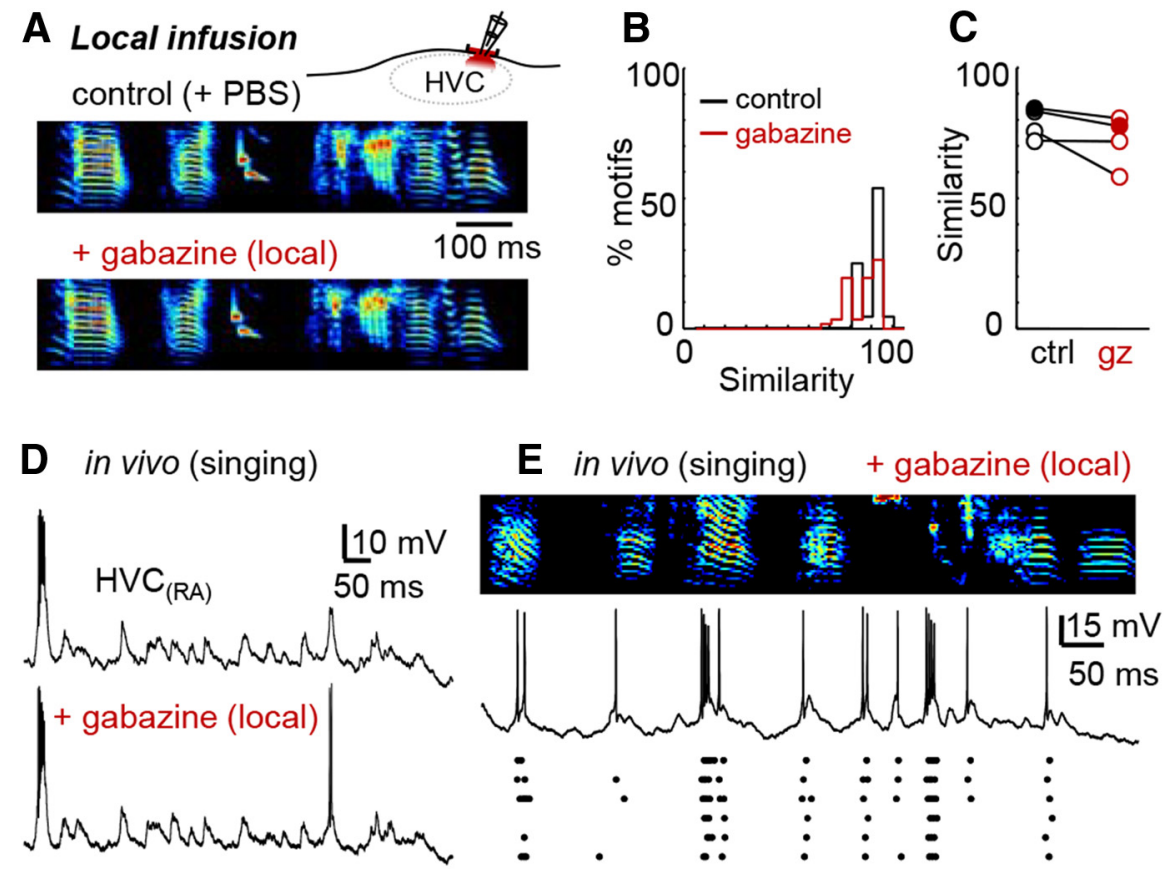

Figure 7. Inhibition is necessary for sparse $\mathrm{HVC}_{(\mathrm{RA})}$ neuron spiking but not temporal precision. $\boldsymbol{A}$, Example of a song motif after of gabazine $(0.05 \mathrm{~mm})$. $\boldsymbol{E}$, Another intracellular recording of an $\mathrm{HVC}_{(\mathrm{RA})}$ neuron after local gabazine infusion (0.05 mm) aligned to singing behavior (example at top, 6 spike trains from that neuron shown below).

excitation may enable sequences of sparsely bursting $\mathrm{HVC}_{(\mathrm{RA})}$ activity during singing.

To test the feasibility of the "structured inhibition and excitation" model (Fig. 1D), we showed that depolarizing current injections into $\mathrm{HVC}_{(\mathrm{RA})}$ neurons during inhibitory gaps in vitro resulted in bursting that strongly resembled activity recorded during singing (Fig. 8E,H; Hahnloser et al., 2002; Long et al., 2010). Similar activation during periods of inhibition resulted in a subthreshold event and increases in current levels did not produce an all-or-none bursting response (Fig. 8I). In this demonstration, we presented the ideal case in which inhibitory interneurons were either spiking synchronously or effectively silenced (during gaps; Fig. $8 \mathrm{C}$ ), leading to clearly structured inhibitory synaptic events in $\mathrm{HVC}_{(\mathrm{RA})}$ neurons (Fig. $8 A, B, D$ ). The possibility remains that gaps within the interneurons projecting to a single $\mathrm{HVC}_{(\mathrm{RA})}$ neuron are not sufficiently aligned to produce this postsynaptic response, which means that we are incapable of ruling out the model that inhibition onto $\mathrm{HVC}_{(\mathrm{RA})}$ neurons is unstructured (Fig. 1C). To test this idea directly, one would have to measure postsynaptic inhibitory currents on HV$\mathrm{C}_{\text {(RA) }}$ neurons during singing, which is not technically feasible given the recording constrains of our intracellular microdrive (Long et al., 2010).

These experiments raise a number of questions concerning inhibitory networks within HVC. One important parameter that is presently unknown is the spatial structure of HVC inhibition. Recent data suggest that interneuron activity may be aligned to specific song elements, forming a representation of syringeal activity within the brain (Amador et al., 2013). Interneurons appear to be locally synchronous (Fig. 3), but the large-scale patterns of inhibitory activity across HVC have not yet been determined. Furthermore, the mechanism underlying the generation of an 

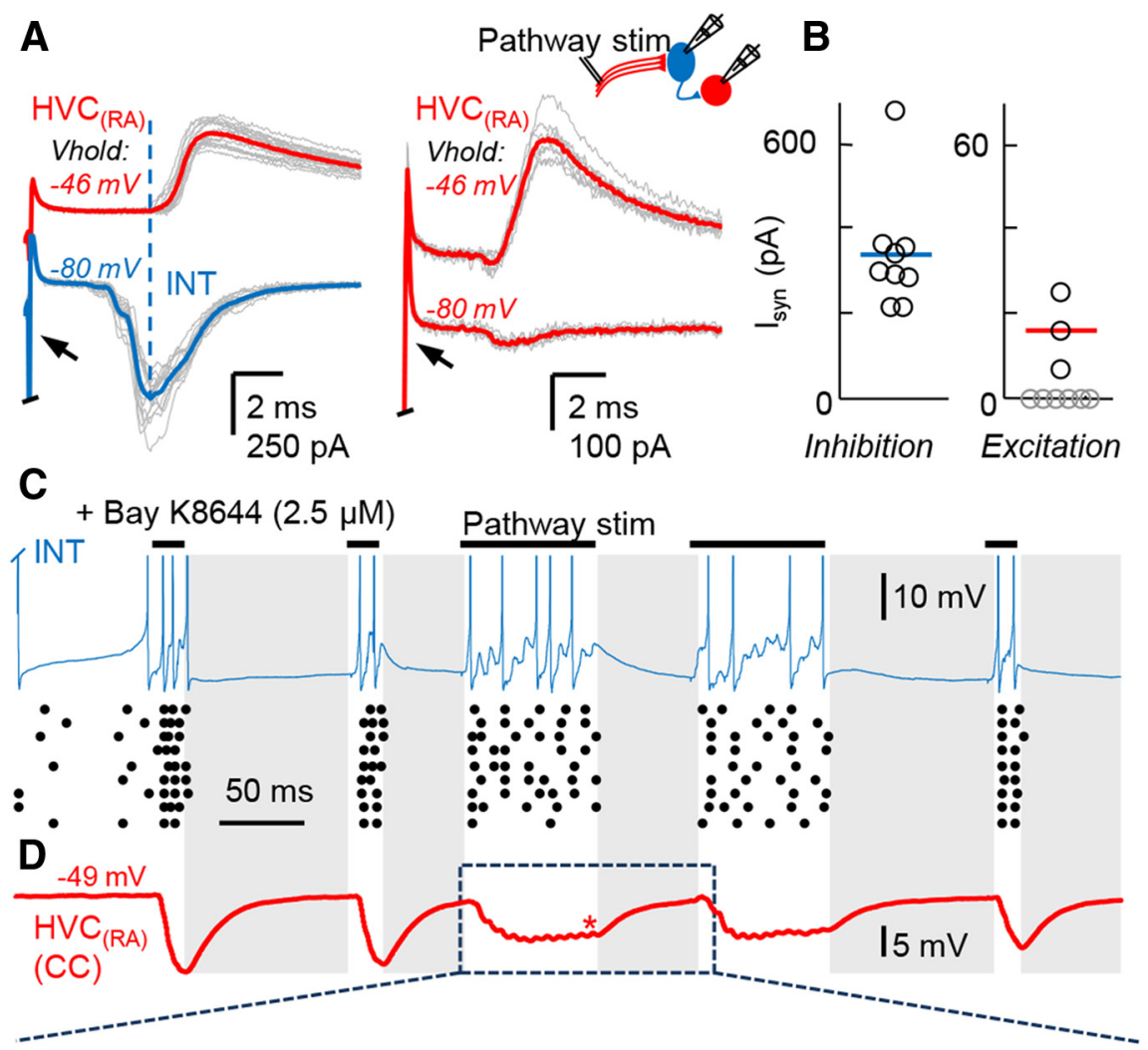

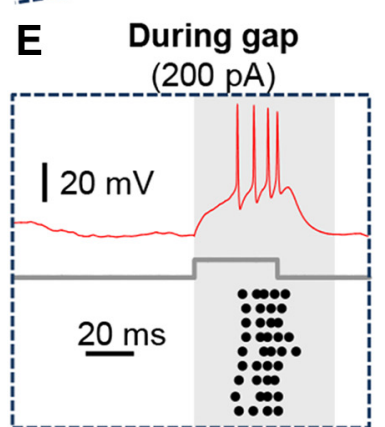

F During inhibition $(200 \mathrm{pA})$

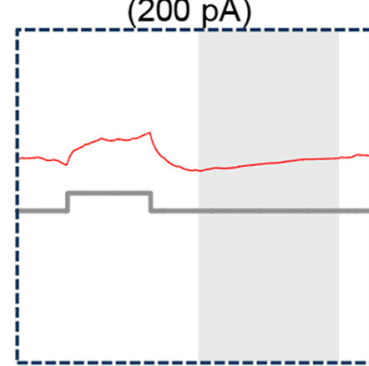

H

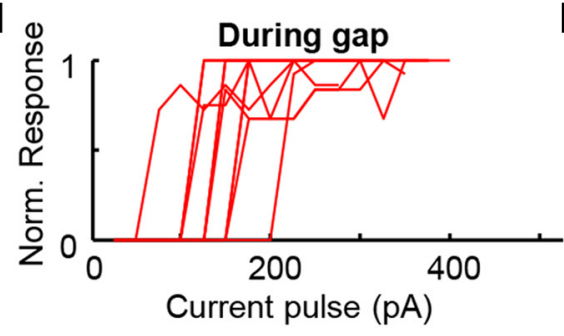

I

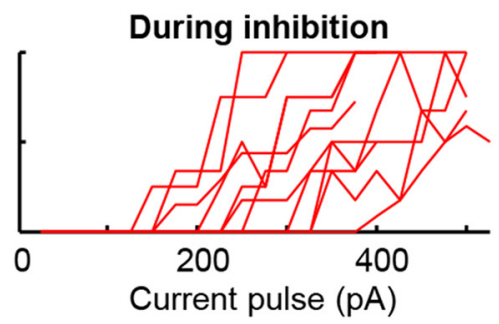

Figure 8. Pauses in interneuron firing can shape $\mathrm{HVC}_{(\mathrm{RA})}$ neuron output. $\boldsymbol{A}$, Stimulation of the HVC-RA fiber tract $(50 \mu \mathrm{A})$ recruits disynaptic inhibition in the $\mathrm{HVC}_{(\mathrm{RA})}$ neuron network. Left, Simultaneous recording of an $\mathrm{HVC}_{(\mathrm{RA})}$ neuron (average trace $=$ red) and an interneuron (average trace $=$ blue). The peak of monosynaptic excitation evoked in the interneuron (dashed blue line) occurs before the onset of the disynaptic inhibitory current in the $\mathrm{HVC}_{(\mathrm{RA})}$ neuron. Right, $\mathrm{An} \mathrm{HVC}_{(\mathrm{RA})}$ neuron in a similar configuration. The disynaptic inhibitory current is abolished at the chloride reversal potential (bottom trace), revealing a small EPSC (stimulation current: $70 \mu \mathrm{A})$. B, Population data from a set of $\mathrm{HVC}_{(\mathrm{RA})}$ neurons recorded in this fashion, with peak IPSC and EPSC strengths quantified at $-46 \mathrm{mV} .3$ of 9 cases exhibited evidence for an excitatory current (average EPSC amplitude: $15.7 \pm 9.0$ $\mathrm{pA}) . \boldsymbol{C}, \boldsymbol{D}$, In vitro recording of an interneuron $(\boldsymbol{C})$ and an $\mathrm{HVC}_{(\mathrm{RA})}$ neuron (D) while stimulating the HVC-RA fiber tract with an extracellular electrode at $60 \mu \mathrm{A}$ (stimulation artifacts clipped for clarity) to evoke interneuron spiking similar to the patterns seen during singing. Gaps in firing are indicated by gray shaded regions. Mean IPSP strength in the $\mathrm{HVC}_{(\mathrm{RA})}$ neuron (measured at location of red star) was $7.8 \pm 2.3 \mathrm{mV}$ ( $n=11$ cells). $\boldsymbol{E}-\boldsymbol{G}$, Configuration as above showing spiking responses in the $\mathrm{HVC}_{(\mathrm{RA})}$ neuron to a 35 ms somatic current pulse during an inhibitory gap $(\boldsymbol{E})$ or ongoing inhibition $(\boldsymbol{F}, \boldsymbol{G})$. $\boldsymbol{H}, \boldsymbol{I}$, Quantification of the $\mathrm{HVC}_{(\mathrm{RA})}$ spiking responses of individual neurons to various current pulses during an inhibitory gap $(\boldsymbol{H})$ and ongoing inhibition $(\boldsymbol{I})$. Each line represents the spiking response of a single neuron to a current pulse normalized to the maximal response from that cell across conditions. All-or-none bursting was only observed during pauses of inhibition. The L-type calcium agonist BAY K8644 was bath-applied to facilitate $\mathrm{HVC}_{(\mathrm{RA})}$ neuron burst firing from somatic current injection in $\mathbf{C}-\boldsymbol{I}$. inhibitory gap remains elusive. Previous in vitro work suggests that HVC interneurons may be capable of generating intrinsic rhythmic activity (Solis and Perkel, 2005) that may contribute to gap generation. A pause in inhibitory firing could also occur because of a lack of excitatory drive or through direct inhibition by another class of GABAergic cells that specifically target other interneurons (Lee et al., 2013; Pi et al., 2013), which may result in "holes" within otherwise dense synaptic inhibition (Karnani et al., 2014).

Our experiments focused exclusively on interneurons and the $\mathrm{HVC}_{(\mathrm{RA})}$ projection population. We did not consider the impact of basal ganglia projection neurons $\left(\mathrm{HVC}_{(\mathrm{X})}\right.$ neurons) on HVC sequence generation, so their role in this process remains unclear. Synaptic connections exist between $\mathrm{HVC}_{(\mathrm{X})}$ neurons and interneurons (Mooney and Prather, 2005), suggesting that $\mathrm{HVC}_{(\mathrm{X})}$ neurons have the capacity to shape the inhibitory firing patterns during singing, thereby indirectly affecting the activity of the $\mathrm{HVC}_{(\mathrm{RA})}$ population. Furthermore, $\mathrm{HVC}_{(\mathrm{X})}$ neurons have also been shown to send sparse monosynaptic excitatory connections onto $\mathrm{HVC}_{(\mathrm{RA})}$ neurons (Mooney and Prather, 2005), providing a direct means of influencing their behavior. With our present dataset, we cannot address directly the role of $\mathrm{HVC}_{(\mathrm{X})}$ neurons in generating premotor sequences, resulting in the need for additional studies.

Most models of HVC function rely on precise feedforward excitatory connectivity to generate sequences within that structure (Li and Greenside, 2006; Jin et al., 2007). Specifically, premotor neurons are thought to be serially connected within HVC, forming a synaptic chain (Long et al., 2010) that constitutes the primary mode of activity propagation through the network. In our previous model, $\mathrm{HVC}_{(\mathrm{RA})} \rightarrow \mathrm{HVC}_{(\mathrm{RA})}$ excitatory connection probabilities range from 0.1 to 1.0 between each sequentially active group of cells (Long et al., 2010), with excitatory connections only existing between these populations. Because we used 70 groups to complete the sequence, the probability of finding a connection between any randomly selected $\mathrm{HVC}_{(\mathrm{RA})}$ $\mathrm{HVC}_{(\mathrm{RA})}$ pair would be $\sim 0.001-0.01$. In our slice experiments, the connection probability between $\mathrm{HVC}_{(\mathrm{RA})}$ neurons was within this range $(0.007)$, corresponding to 1 connection of 140 tested. We were somewhat surprised by the lack of premotor interconnectivity given a previous study that found four $\mathrm{HVC}_{(\mathrm{RA})}$ 
$\rightarrow \mathrm{HVC}_{(\mathrm{RA})}$ pairs and a connection probability of 0.11 (Mooney and Prather, 2005). Taking our connectivity numbers at face value and assuming a total number of $\sim 40,000 \mathrm{HVC}_{(\mathrm{RA})}$ neurons in each hemisphere (Wang et al., 2002), we would estimate that individual $\mathrm{HVC}_{(\mathrm{RA})}$ neurons may receive direct contacts from $\sim 300$ other $\mathrm{HVC}_{(\mathrm{RA})}$ neurons. This number, however, is likely to represent an upper bound because it assumes that connection probability estimated from closely spaced pairs (as measured in our study and previous recordings from Mooney and Prather, 2005) could be extrapolated to the entire nucleus. Future work using viral techniques to quantify connectivity numbers (Wickersham et al., 2007) may help to shed light on the number and relative position of presynaptic $\mathrm{HVC}_{(\mathrm{RA})}$ neurons.

In a previous study (Long et al., 2010), we measured an average of 10 stereotyped excitatory synaptic events that were active throughout the song and were separate from the depolarization preceding the burst. To ensure reliable sparse sequences in the presence of multiple excitatory inputs, we previously speculated that spatial convergence onto dendrites of $\mathrm{HVC}_{(\mathrm{RA})}$ neurons may allow the selection of only one of these events to elicit an all-ornone burst (Long et al., 2010). Given the results of the present study, we propose an additional powerful mechanism of input selection: local HVC interneurons may form an inhibitory mask that can greatly constrain the spiking activity of $\mathrm{HVC}_{(\mathrm{RA})}$ neurons. Because each premotor burst ultimately leads to the activation of muscles involved in producing the song at a given moment (Fee et al., 2004), inhibition may be pruning away a range of motor possibilities to establish a one-to-one relationship between $\mathrm{HVC}_{(\mathrm{RA})}$ neurons and temporally localized motor commands. Our findings support a class of circuit models in which patterned inhibition can actively shape premotor sequence generation that may be broadly applicable across systems.

\section{References}

Amador A, Perl YS, Mindlin GB, Margoliash D (2013) Elemental gesture dynamics are encoded by song premotor cortical neurons. Nature 495: 59-64. CrossRef Medline

Berens P (2009) CircStat: A MATLAB toolbox for circular statistics. J Stat Software 31:1-21.

Daou A, Ross MT, Johnson F, Hyson RL, Bertram R (2013) Electrophysiological characterization and computational models of HVC neurons in the zebra finch. J Neurophysiol 110:1227-1245. CrossRef Medline

Deniau JM, Chevalier G (1985) Disinhibition as a basic process in the expression of striatal functions. II. The striato-nigral influence on thalamocortical cells of the ventromedial thalamic nucleus. Brain Res 334:227-233. CrossRef Medline

Dutar P, Vu HM, Perkel DJ (1998) Multiple cell types distinguished by physiological, pharmacological, and anatomic properties in nucleus $\mathrm{HVc}$ of the adult zebra finch. J Neurophysiol 80:1828-1838. Medline

Fee MS, Kozhevnikov AA, Hahnloser RH (2004) Neural mechanisms of vocal sequence generation in the songbird. Ann N Y Acad Sci 1016:153-170. CrossRef Medline

Fino E, Yuste R (2011) Dense inhibitory connectivity in neocortex. Neuron 69:1188-1203. CrossRef Medline

Gibb L, Gentner TQ, Abarbanel HD (2009) Inhibition and recurrent excitation in a computational model of sparse bursting in song nucleus HVC. J Neurophysiol 102:1748-1762. CrossRef Medline

Guitchounts G, Markowitz JE, Liberti WA, Gardner TJ (2013) A carbonfiber electrode array for long-term neural recording. J Neural Eng 10: 046016. CrossRef Medline

Hahnloser RH, Kozhevnikov AA, Fee MS (2002) An ultra-sparse code underlies the generation of neural sequences in a songbird. Nature 419:65-70. CrossRef Medline

Hahnloser RH, Kozhevnikov AA, Fee MS (2006) Sleep-related neural activity in a premotor and a basal-ganglia pathway of the songbird. J Neurophysiol 96:794-812. CrossRef Medline
Harvey CD, Coen P, Tank DW (2012) Choice-specific sequences in parietal cortex during a virtual-navigation decision task. Nature 484:62-68. CrossRef Medline

Jin DZ, Ramazanoğlu FM, Seung HS (2007) Intrinsic bursting enhances the robustness of a neural network model of sequence generation by avian brain area HVC. J Comput Neurosci 23:283-299. CrossRef Medline

Jones LM, Fontanini A, Sadacca BF, Miller P, Katz DB (2007) Natural stimuli evoke dynamic sequences of states in sensory cortical ensembles. Proc Natl Acad Sci U S A 104:18772-18777. CrossRef Medline

Kapfer C, Glickfeld LL, Atallah BV, Scanziani M (2007) Supralinear increase of recurrent inhibition during sparse activity in the somatosensory cortex. Nat Neurosci 10:743-753. CrossRef Medline

Karnani MM, Agetsuma M, Yuste R (2014) A blanket of inhibition: functional inferences from dense inhibitory connectivity. Curr Opin Neurobiol 26:96-102. CrossRef Medline

Kozhevnikov AA, Fee MS (2007) Singing-related activity of identified HVC neurons in the zebra finch. J Neurophysiol 97:4271-4283. CrossRef Medline

Kubota M, Taniguchi I (1998) Electrophysiological characteristics of classes of neuron in the HVc of the zebra finch. J Neurophysiol 80:914-923. Medline

Lee S, Kruglikov I, Huang ZJ, Fishell G, Rudy B (2013) A disinhibitory circuit mediates motor integration in the somatosensory cortex. Nat Neurosci 16:1662-1670. CrossRef Medline

Li M, Greenside H (2006) Stable propagation of a burst through a onedimensional homogeneous excitatory chain model of songbird nucleus HVC. Phys Rev E Stat Nonlin Soft Matter Phys 74:011918. CrossRef Medline

Long MA, Fee MS (2008) Using temperature to analyse temporal dynamics in the songbird motor pathway. Nature 456:189-194. CrossRef Medline

Long MA, Jin DZ, Fee MS (2010) Support for a synaptic chain model of neuronal sequence generation. Nature 468:394-399. CrossRef Medline

Mooney R (2000) Different subthreshold mechanisms underlie song selectivity in identified HVc neurons of the zebra finch. J Neurosci 20:54205436. Medline

Mooney R, Prather JF (2005) The HVC microcircuit: the synaptic basis for interactions between song motor and vocal plasticity pathways. J Neurosci 25:1952-1964. CrossRef Medline

Murayama M, Pérez-Garci E, Nevian T, Bock T, Senn W, Larkum ME (2009) Dendritic encoding of sensory stimuli controlled by deep cortical interneurons. Nature 457:1137-1141. CrossRef Medline

Nixdorf BE, Davis SS, DeVoogd TJ (1989) Morphology of Golgi-impregnated neurons in hyperstriatum ventralis, pars caudalis in adult male and female canaries. J Comp Neurol 284:337-349. CrossRef Medline

Nottebohm F, Stokes TM, Leonard CM (1976) Central control of song in the canary, Serinus canarius. J Comp Neurol 165:457-486. CrossRef Medline

Nottebohm F, Kelley DB, Paton JA (1982) Connections of vocal control nuclei in the canary telencephalon. J Comp Neurol 207:344-357. CrossRef Medline

Pastalkova E, Itskov V, Amarasingham A, Buzsáki G (2008) Internally generated cell assembly sequences in the rat hippocampus. Science 321:13221327. CrossRef Medline

Peters AJ, Chen SX, Komiyama T (2014) Emergence of reproducible spatiotemporal activity during motor learning. Nature 510:263-267. CrossRef Medline

Pi HJ, Hangya B, Kvitsiani D, Sanders JI, Huang ZJ, Kepecs A (2013) Cortical interneurons that specialize in disinhibitory control. Nature 503: 521-524. CrossRef Medline

Poole B, Markowitz JE, Gardner TJ (2012) The song must go on: resilience of the songbird vocal motor pathway. PloS one 7:e38173. CrossRef Medline

Scotto-Lomassese S, Rochefort C, Nshdejan A, Scharff C (2007) HVC interneurons are not renewed in adult male zebra finches. Eur J Neurosci 25:1663-1668. CrossRef Medline

Silberberg G, Markram H (2007) Disynaptic inhibition between neocortical pyramidal cells mediated by Martinotti cells. Neuron 53:735-746. CrossRef Medline

Solis MM, Perkel DJ (2005) Rhythmic activity in a forebrain vocal control nucleus in vitro. J Neurosci 25:2811-2822. CrossRef Medline 
Stauffer TR, Elliott KC, Ross MT, Basista MJ, Hyson RL, Johnson F (2012) Axial organization of a brain region that sequences a learned pattern of behavior. J Neurosci 32:9312-9322. CrossRef Medline

Tanji J (2001) Sequential organization of multiple movements: involvement of cortical motor areas. Annu Rev Neurosci 24:631-651. CrossRef Medline

Tchernichovski O, Nottebohm F, Ho CE, Pesaran B, Mitra PP (2000) A procedure for an automated measurement of song similarity. Anim Behav 59:1167-1176. CrossRef Medline

Vu ET, Mazurek ME, Kuo YC (1994) Identification of a forebrain motor programming network for the learned song of zebra finches. J Neurosci 14:6924-6934. Medline

Wang N, Hurley P, Pytte C, Kirn JR (2002) Vocal control neuron incorporation decreases with age in the adult zebra finch. J Neurosci 22:1086410870. Medline
Wickersham IR, Lyon DC, Barnard RJ, Mori T, Finke S, Conzelmann KK, Young JA, Callaway EM (2007) Monosynaptic restriction of transsynaptic tracing from single, genetically targeted neurons. Neuron 53:639647. CrossRef Medline

Wild JM, Williams MN, Howie GJ, Mooney R (2005) Calcium-binding proteins define interneurons in HVC of the zebra finch (Taeniopygia guttata). J Comp Neurol 483:76-90. CrossRef Medline

Wilent WB, Nitz DA (2007) Discrete place fields of hippocampal formation interneurons. J Neurophysiol 97:4152-4161. CrossRef Medline

Yildiz IB, Kiebel SJ (2011) A hierarchical neuronal model for generation and online recognition of birdsongs. PLoS Comput Biol 7:e1002303. CrossRef Medline

Yu AC, Margoliash D (1996) Temporal hierarchical control of singing in birds. Science 273:1871-1875. CrossRef Medline 